\title{
BREAST AUGMENTATION AND BREAST IMPLANTS EVOLUTION
}

\author{
Yordan Yordanov \\ Unit of Plastic Surgery and Burns, Military Medical Academy of Sofia
}

\begin{abstract}
The female breast is a universal symbol of sexuality, motherhood and femininity today, dating back even to the time of ancient cave paintings. Historically, women have long sought breast enlargement to improve physical proportions, to foster a more feminine appearance, or to enhance self-image. When compared to the aesthetic norm, inadequate breast volume may lead to a negative body image, feelings of inadequacy, and low self-esteem. These disturbances may adversely affect a patient's interpersonal relationships, sexual fulfillment, and quality of life. Since its introduction in 1962, modern breast augmentation with implants has become one of the most common aesthetic procedures, receiving more media attention than any other. It remains an increasingly popular surgical intervention today where the idealised female physique has morphed from the curvaceous Rubens type to one increasingly thin and androgynous, but with prominent breasts. The popularity of the procedure is thought to be based on the satisfaction of the patients' results. Breast enlargement and reshaping with breast implants nowadays is a safe, well-accepted technique, which can be undertaken with ever-less frequent complications thanks to continued advances in both surgical technique and implant design. The purpose of the present article is to make a brief review of the history of breast augmentation as a surgical procedure and the evolution of breast implants.
\end{abstract}

Keywords: breast augmentation, breast implants, anatomic-shaped, cohesive silicone gel, form-stable

\section{INTRODUCTION}

Female glandular hypomastia is a frequently encountered disorder that affects a significant number of women worldwide and may occur as a developmental or involutional process. Developmental hypomastia is often seen as primary mammary hypoplasia or as a sequela of thoracic hypoplasia (Poland syndrome) or other chest wall deformity. Involutional hypomastia may develop in the postpartum

\footnotetext{
Address for correspondence:

Yordan P. Yordanov, PhD

Unit of Plastic Surgery and Burns,

Military Medical Academy of Sofia

3 Georgi Sofiiski Blvd.

1606 Sofia, Bulgaria

e-mail:yordanov_vma@abv.bg
}

Received: January 23, 2014

Accepted: February 11, 2014 setting and may be exacerbated by breast-feeding or significant weight loss. When compared to the norm, inadequate breast volume may lead to a negative body image, feelings of inadequacy, and low self-esteem (1). These disturbances may adversely affect a patient's interpersonal relationships, sexual fulfillment, and quality of life (2). Historically, women have long sought breast enlargement to improve physical proportions, to foster a more feminine appearance, or to enhance self-image.

Following the introduction of the silicone gel prosthesis in 1962 (3), breast augmentation has become one of the most frequently performed operations in plastic surgery (4). It is estimated that more than $1 \%$ of the adult female population in the United States has undergone breast augmentation (5). In Bulgaria, similar to the majority of the European countries, such statistics are still missing. The women undergoing breast augmentation have been scientifically scrutinised since its inception and found 
to range from outgoing healthy individuals with a desire for aesthetic improvement to women with depression, low self-esteem, negative body image, and sexual inhibitions $(1,2)$ The popularity of the procedure is thought to be based on the satisfaction of the patients' results (6). Women in general have enhanced self-image, increased self-assurance, improved sexual functioning, and better interpersonal relationships after augmentation (7).

\section{The evolution of breast augmentation}

The first report of successful breast augmentation appeared in 1895 in which Czerny described transplanting a lipoma from the trunk to the breast in a patient deformed by a partial mastectomy (8). In 1954, Longacre described a local dermal-fat flap for autogenous augmentation of the breast (9). Eventually, both adipose tissue and omentum were also used to augment the breast. However, the clinical results of using autogenous tissue for breast augmentation were often unpredictable and unacceptable (10).

During the 1950s and 1960s, breast augmentation with solid alloplastic materials was carried out using polyurethane, polytetrafluoroethylene (Teflon), and expanded polyvinyl alcohol formaldehyde (Ivalon sponge). Ultimately, the use of these materials was discontinued as the majority of patients developed local tissue reactions, firmness, distortion of the breast, and significant discomfort (11). Various other solid and semisolid materials have been injected directly into the breast parenchyma for augmentation, including petroleum jelly, beeswax, shellac, and epoxy resin (12). Uchida reported the use of injectable silicone in 1961 (13). Injection of liquid silicone resulted infrequent complications, including recurrent infections, chronic inflammation, drainage, granuloma formation, and even necrosis $(14,15)$. Because of these complications, breast augmentation by injection of free liquid silicone was abandoned.

The introduction of the silicone gel breast implants in 1962 by Cronin and Gerow (3) marked the beginning of the modern era of breast augmentation. The silicone gel implants commercially available today are in general a refined and safer device than their predecessors.
Liquid silicone (poly-dimethyl siloxane) was originally developed in the aeronautics to meet the needs of the aircraft-engineering industry during World War II. Because of its softness and inert nature, it attracted interest from the medical sector and was soon evaluated as an implantable medical device by plastic surgical researchers $(16,17)$. The Cronin and Gerow mammary implant of the 1960s, which was manufactured by Dow Corning (Midland, Michigan, USA) (3), was composed of a viscous silicone gel contained within a thick silicone shell in the shape of a teardrop. Seams were present at the periphery of the device, and Dacron fixation patches were placed on the posterior surfaces to help ensure proper position (Fig. 1). These early devices had such a high incidence of capsular contracture that a new generation of silicone implants was developed by various manufacturers in the mid to late 1970 s to produce a more natural result. These implants were round and characterized by a seamless, thin, smooth silicone shell. There were no fixation patches, and the silicone gel was less viscous than in first-generation implants. Whereas the incidence of capsular contracture may have been improved somewhat, the incidence of silicone gel "bleed" and shell rupture was enhanced, especially from manufacturers who made very thin shells (18). Gel bleed is a phenomenon whereby low-molecular-weight particles of silicone gel diffuse or leak through the silicone elastomer shell, giving a sticky feel to the surface. It has been found that silicone bleed could promote capsule contracture (19). Whether it is caused by silicone bleed or other factors, capsule contracture has been the biggest clinical problem with the use of smooth-surfaced silicone gel implants (4).

The third generation of smooth-surfaced silicone implants, developed in the early to mid-1980s, focused on improving the strength and integrity of the silicone shell and on minimising the silicone bleed phenomenon $(17,18)$. This generation of implants was characterized by two layers of high-performance elastomer with a thin fluorosilicone barrier coat in between. There is data to suggest that these improvements enhanced shell life and lessened capsule contracture. Third-generation silicone gel implants with the application of a textured 
Breast Augmentation and Breast Implants Evolution
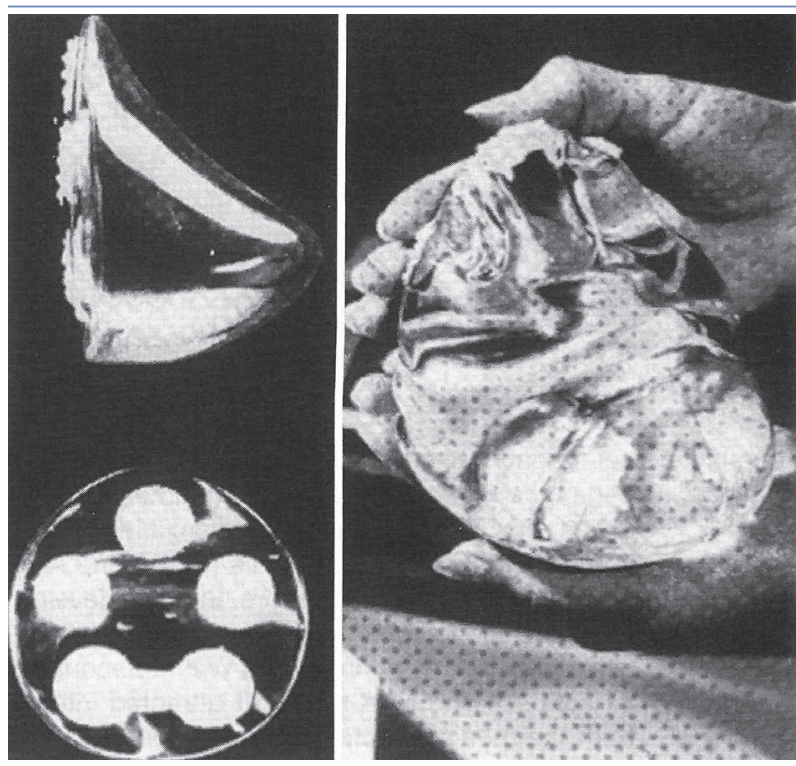

Fig. 1. The original Cronin-Gerow silicone implant introduced in 1962 with teardrop shape, smooth surface, and Dacron patches on the posterior surface to help maintain the implant's position (3)

surface can be considered fourth-generation devices, and cohesive silicone gel-filled implants can be considered fifth-generation devices. Although criticised for imprecision and overlap, the "generational" system serves as a useful guide to implant evolution (Fig. 2) (20). The fifth-generation implants are discussed in more details below.

\section{Inflatable implants}

The inflatable saline-filled implant was first reported by Arion in France in 1965 (21). Its invention and development allowed smaller incisions through which a noninflated device could be inserted and then inflated with liquid filler material. Saline implants were subsequently developed by American manufacturers and underwent clinical evaluation in the early 1970s (22). The emphasis for the application of these devices was focused on their inflatable nature, allowing smaller incisions, not on the character or safety of the liquid filler or an attempt to lessen the rates of capsular contracture.

Although it is generally accepted that the contracture rate with saline implants is relatively low, two qualities of these devices have plagued their clinical use. The foremost was their deflation rate. In 1968 American manufacturer Heyer-Schulte de-

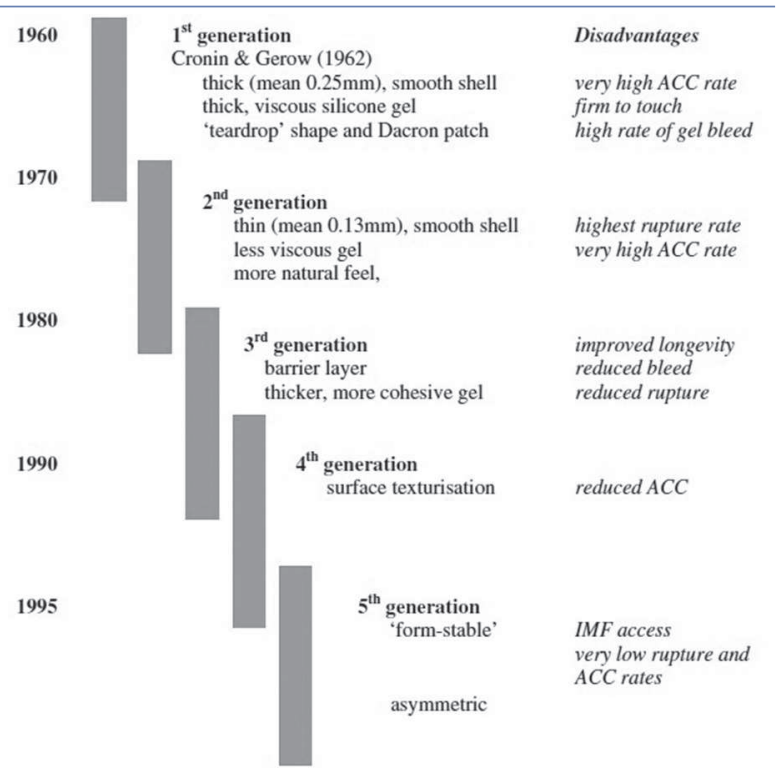

Fig. 2. Five generations of silicone gel mammary implants (after Independent Review Group). ACC-adverse capsular contracture; IMF- infra-mammary fold (20)

veloped a saline implant with thicker and cured by a room-temperature vulcanized process shell (4). This significantly decreased the deflation rate (23). The second factor found to increase deflation rates was valve failure (24). The original HeyerSchulte prosthesis had a retention (leaflet) valve, which was subsequently replaced by a diaphragm valve. Saline implants currently manufactured by Mentor (which purchased Heyer-Schulte) and Allergan (formerly INAMED and McGhan Medical) have diaphragm valves and room-temperature vulcanised cured shells.

The other characteristic of saline implants that has been a problem relates to the saline itself, which may transmit visible surface wrinkles and a knuckle-like feel in volumetrically underfilled devices. When the device is overfilled, it may feel and look like a firm ball and transmit a peripheral "scalloping" look. For these reasons, saline implants historically perform better under thicker tissue, and surgeons generally fill implants to the recommended volume or just beyond. It was also demonstrated that filling the implants within the recommended range or overfilling them increased device longevity and had a statistically significant effect on the 
implants' 10-year survival rate (25). Saline implants are also heavier than silicone gel implants on a volumetric basis and may cause more tissue thinning with inferior displacement of the implant over time (4).

\section{Double-lumen implants}

The original double-lumen implant was developed by Hartley as a means of countering capsular contracture (26). It was constructed of an inner silicone gel-filled lumen surrounded by an outer saline inflatable shell. The concept of the device is the initial inflation of the outer saline shell to make a larger pocket, with subsequent percutaneous deflation to leave the smaller silicone gel-filled shell within a larger pocket. The device became popular without going through these machinations as a fixed-volume, two-chamber device or as a drug delivery device, which allowed the addition of steroids or antibiotics to the outer saline-filled chamber.

Cox-Uphoff developed a "reverse doublelumen" implant, which had an outer silicone gelfilled shell surrounding an inner inflatable shell (27). Today, an example of double-lumen device on the market is the Mentor Becker prosthesis- an expander-implant used primarily for reconstruction (28). This device was originally developed as a saline device but was subsequently converted to a reverse gel and saline double-lumen design to minimize deflation rates. The implant functions initially as a tissue expander. Once the correct size has been obtained, the injection dome is removed, leaving the implant in position.

\section{Texturized Implants}

Early attempts at augmentation with polyurethane sponge were not successful, but in 1970, Ashley reported the favorable use of a silicone gel implant covered with a thin layer of polyurethane foam (29). Although the foam was placed on the implant primarily to maintain its position, clinical use seemed to show a lessened incidence of capsular contracture (30). In the 1980s, it was reported that polyurethane covered silicone gel implants produced aesthetically satisfactory results with low capsular contracture rates $(31,32)$. The polyurethane surface adhered to the surrounding tissues, subsequently delaminated, and created a relatively non- contractible capsule (33). Unlike smooth-surfaced implants that had to be mobile within their pocket, polyurethane-covered implants could be immobile yet soft. These devices had reached a zenith of popularity by 1990, when questions of the safety of polyurethane foam breakdown products caused their withdrawal from the breast implant market (34).

The favorable clinical outcomes and commercial success of polyurethane-covered implants led manufacturers to develop textured silicone surfaces in the hope of achieving similar results (Fig. 3) (35). In 1986, McGhan Medical introduced Biocell textured implants and expanders, and Mentor introduced Siltex textured implants. These textured surfaces remain available today. In 1990, Dow Corning introduced its MSI "structured surface", but the company withdrew from the market two years later.

Biocell is an aggressive open-pore textured silicone surface composed of irregular pores $(4,36)$. Similar to the polyurethane implants, "immobility with softness" characterizes Biocell-covered implants. Prospective clinical studies have demonstrated that Biocell textured implants have a significantly lower incidence of capsule contracture than do their smooth counterparts, whether they are filled with silicone gel or saline $(37,38)$.

Siltex is a less aggressive textured silicone surface created as a negative contact imprint off texturing foam (Fig. 3) (35). Siltex does not adhere to the surrounding tissue and is not characterized by immobility with softness, as are polyurethane and Biocell (36). Whereas Siltex-covered implants move within their surrounding pocket similar to smoothwalled implants, prospective clinical studies have shown a significantly lower incidence of capsule contracture compared with their smooth counterparts, whether they are filled with silicone gel or saline $(39,40)$.

Other textured-surface devices that are currently available are the polyurethane foam-covered implants manufactured by Silimed in Brazil (41).

\section{Alternative filler implants}

When safety issues with silicone gel implants became a concern, investigators looked for alternative filler substances. Among all the investigat- 


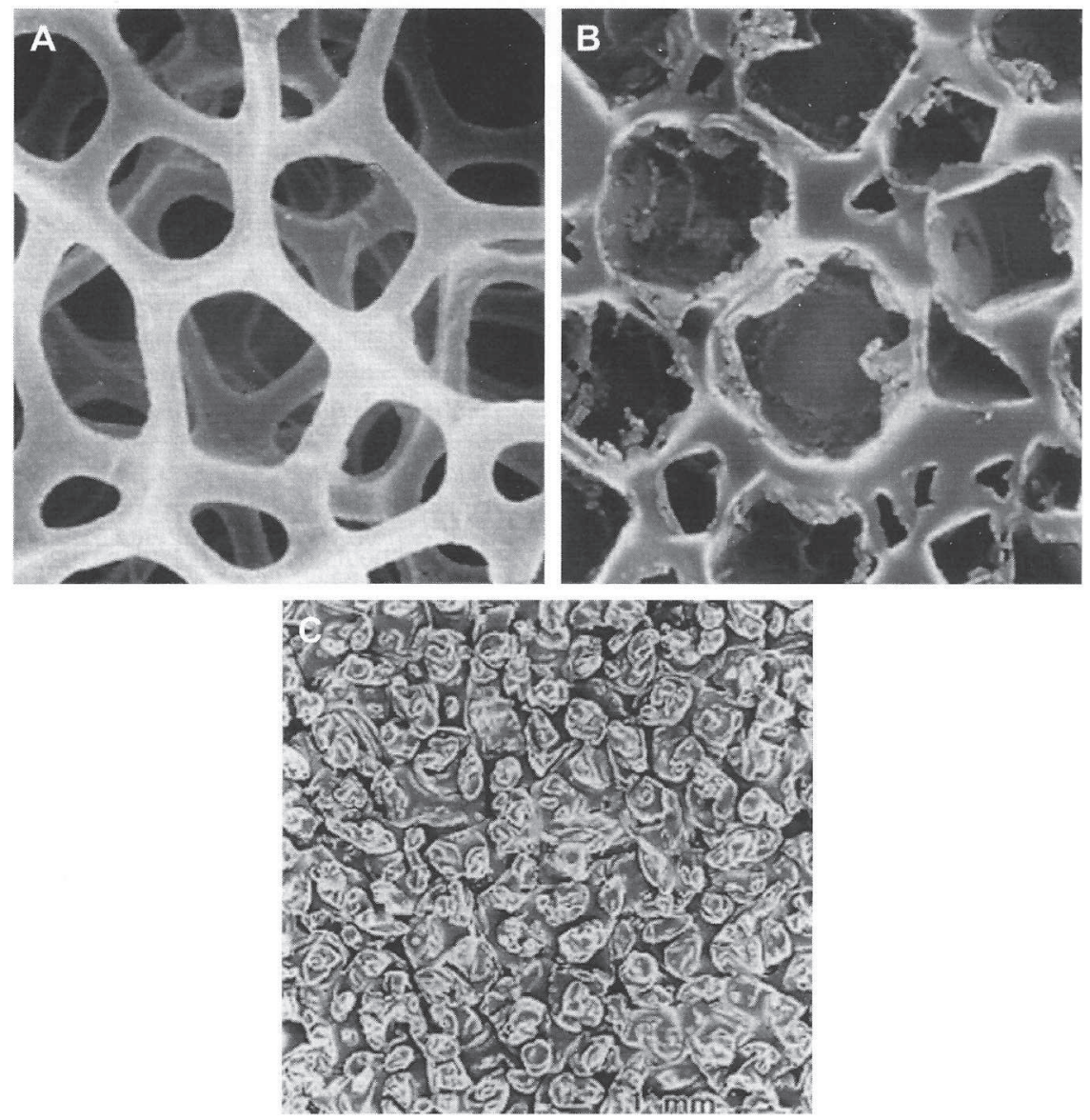

Fig. 3. (A) Polyurethane foam gains tissue adherence and delaminates from the implant. This texture fostered the development of textured silicone surfaces. (B) Biocell is an aggressive silicone textured surface that adheres to surrounding tissue by an adhesive effect. (C) Siltex is a less aggressive silicone textured surface that does not demonstrate any adhesive effect and does not gain tissue adherence (35)

ed options, three actually came to market. Polyvinylpyrrolidone is a low-molecular weight "bio-oncotic" gel thought to be more radiolucent than silicone. It composed the fill material of the Misti Gold implant introduced in 1991 by Bioplasty (42). The polyvinylpyrrolidone implant is currently still available under the name NovaGold. In December 2000, the British Medical Devices Agency issued a device alert regarding this implant and other alternative filler devices, citing the opinion that studies demonstrating the safety of these devices are lacking (43).

LipoMatrix manufactured triglyceride-filled implants termed "trilucent implants" in 1994. Soybean oil composed the fill material, which was said to be radiolucent. Problems with oil bleed (44), tissue irritation, and a rancid or foul smell (45) were reported, and the implants were withdrawn from the market in 1999.

Hydrogel implants are filled with an organic polymer, which is a mixture of polysaccharide and water. These implants have been manufactured in France by PIP and Arion. There have been reports of swelling of hydrogel (and polyvinylpyrrolidone) implants after implantation caused by osmotic gradient pressure $(4,43)$. The British Medical Devices Agency alert of 2000 also applied to these devices.

\section{Form-stable silicone gel implants}

All silicone gel implants are cross-linked to maintain a gel consistency, and all silicone gel has cohesive properties. As the cross-linking increases, the consistency or firmness of the liquid-feeling gel changes to that of a soft cheese. The enhanced cohe- 
sive nature of these implants makes them form-stable. Thus the implant maintains its shape in all positions (shape maintenance). These implants are designed in various anatomic dimensions in addition to round shapes and are collectively referred to as "cohesive silicone gel implants". These formstable implants are currently popular worldwide and undergoing Food and Drug Administration (FDA)approved clinical trials in the United States (41).

\section{Anatomic-shaped implants}

The original Cronin and Gerow silicone gel implants had a tear-drop shape, as did a number of the early saline- and gel-filled devices. Problems with capsular contracture, however, led manufacturers to design round, smooth-surfaced low-profile implants, which move within their surgical pockets. These round smooth designs dominated the market for nearly 20 years. Only when the phenomenon of immobility with softness was appreciated was the creation of anatomic devices clinically appropriate $(4,39-45)$ The polyurethane Optimum and Replicon devices were early generation anatomic-shaped implants popular in the 1980s $(30,46)$. These implants are no longer available.

The tissue adherence observed with tissue expanders that had the Biocell surface led McGhan to develop anatomically shaped expanders and subsequently an internally stacked Style 153 gel anatomic-shaped implant (4). Favorable clinical experience and advanced product design led to a matrix of variable height-towidth ratio anatomic expanders and implants, the Style 133 expanders and Style 410 Matrix cohesive implants (Fig. 4). The latter enjoy widespread international use in aesthetic surgery $(41,47)$.

Mentor introduced a midheight Siltex anatomic shaped tissue expander in 1997 and other height options in 2003 (4). Because tissue adherence does not generally occur, the pocket must be exact and only minimally larger than the footprint of the reduced height device to minimize the possibility of implant rotation (48). The Mentor CPG (Contour Profile Gel) implant is Mentor's highly cohesive form stable gel-filled implant. Designed to compete with Allergan's style 410, initially there was only a single size of the CPG. It now comes in a variety of heights and projections. The CPG gel is formulated to be a little softer than the 410 (Fig. 5) (49).

Nowadays Silimed (Brazil) markets polyurethane-covered cohesive silicone gel implants in anatomic shapes (34) that enjoy international popularity.

Anatomic-shaped saline inflatable implants are manufactured by both Mentor and Inamed (McGhan).

Implant regulations - safety and efficacy of silicone breast implants

In 1976, the US Congress passed a Medical Device Amendment to the Food, Drug, and Cosmetic Act that gave the FDA authority over medical devices. Implants on the market in the United States at the time or those considered "substantially equivalent" to those marketed before 1976 were grandfathered in and allowed to remain in use until the FDA could formally review their safety and efficacy. In 1988, the FDA called for the manufacturers of silicone gel-filled implants to submit their Premarket Approval Applications containing data adequate to substantiate the safety and efficacy of the devices they were marketing. In November 1991, the FDA convened an advisory panel of experts to hold public hearings and evaluate the manufacturers' data. The panel concluded that more research was necessary in order to establish safety and efficacy but recommended continued availability of plants while that research was performed. In January 1992, however, the FDA Commissioner went against the recommendation of the advisory panel and called for a voluntary moratorium on the use of silicone gel implants. After further evaluation of the situation by the advisory panel (who thought there was a public need for the devices), the FDA Commissioner, in April 1992, ruled that although silicone breast implants were not necessarily unsafe, the law required more data to substantiate safety and efficacy than the manufacturers had supplied $(50,51)$. The use of silicone gel implants was restricted to clinical trials until the data was produced. This was interpreted by the media and the public at large that silicone gel implants were "banned" because they were not safe. This effectively took silicone gel implants off 
Breast Augmentation and Breast Implants Evolution
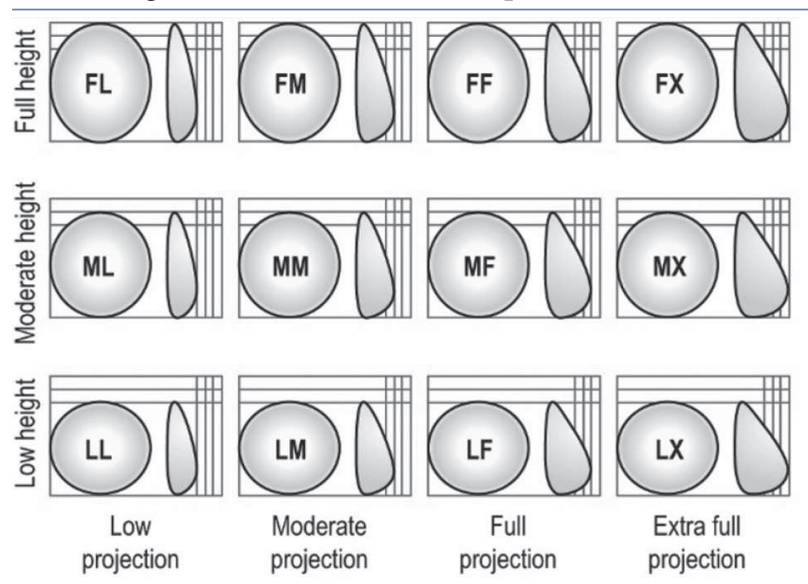

Fig. 4. Allergan's style 410 was the first highly cohesive formstable gel filled implant developed. The 410 product line includes 12 different shapes for any given volume. These 12 shapes make up what they call the "410 Matrix" (49)

the market for breast augmentation in the United States for the next 12 years.

The moratorium on silicone breast implant use instituted in 1992 against the advice of the FDA expert panel demonstrated the contentious nature of the controversy surrounding silicone implants and associated disorders such as connective tissue diseases and breast cancer. Because of the scale of this controversy, breast implants have become the single most investigated medical implant device. Numerous large-scale epidemiologic studies have shown no statistically significant relevant increased risk of connective tissue disease in women who have undergone breast augmentation or reconstruction with silicone gel implants (49).

A literature review on the subject demonstrated numerous anecdotal and clinical reports from the 1980s and 1990s which hypothesize the possibility of an immunologic reaction from silicone exposure. More recently, however, comprehensive literature reviews such as that by Holmich et al (52), reinforce the large epidemiological studies and meta-analyses which conclude similarly that there is no connection between silicone implants and defined connective tissue diseases or atypical, undefined connective tissue syndromes.

Questions about the relationship of implants to breast cancer have also been raised over the years and anecdotal reports have suggested possi-

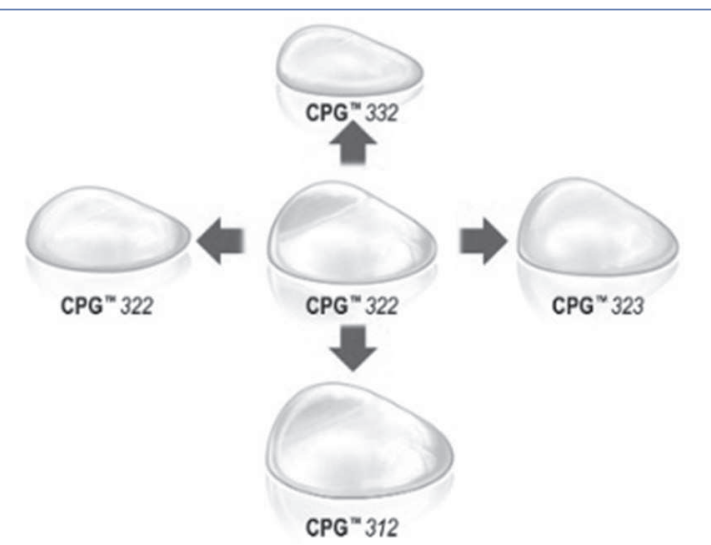

CPG" Naming Legend

\begin{tabular}{|c|c|c|}
\hline $\begin{array}{c}\text { Cohesive } \\
\text { level }\end{array}$ & $\begin{array}{c}\text { Implant } \\
\text { height }\end{array}$ & $\begin{array}{c}\text { Implant } \\
\text { projection }\end{array}$ \\
\hline III & Tall & High \\
3 & 3 & 3 \\
\hline II & Medium & Moderate \\
2 & 2 & 2 \\
\hline I & Low & Moderate \\
1 & 1 & 1 \\
\hline
\end{tabular}

Key: Digit $1=$ Cohersive level Digit 2 = Height of implant Digit $3=$ Projection of implant

Fig. 5. The Mentor CPG (Contour Profile Gel) implant is Mentor's highly cohesive form stable gel-filled implant which was designed to compete with Allergan's style 410 (49)

ble links. Delayed detection and decreased survival rates in breast cancer are common concerns for women contemplating breast augmentation. Deapen methodically reviewed 21 cohort and case-control studies, representing nine different populations from around the world (53). The data from numerous locations in the United States as well as Denmark, Sweden, Finland, Canada, Australia and Scotland consistently demonstrated no increased risk of cancer. In fact in many studies the relative risk was decreased. Furthermore, the risk of delayed detection and poorer prognosis was not borne out with any consistent evidence. However, it must be noted that there are reports demonstrating that screening mammography is slightly impaired in patients with silicone or saline implants (54). The false negative rate can be higher as less tissue is visualised. Women with breast implants require special displacement techniques (i.e. the Eklin protocol) to increase the efficacy of mammography and may 
also require additional testing such as ultrasound or MRI to complete the workup of a questionable finding Mammography, however, remains the first line diagnostic tool of choice for these women. Despite the increased difficulty in screening patients with breast augmentation, many studies have demonstrated that tumor size, disease stage, recurrence rates and survival remain equal in augmented patients (49).

Just as reassuring are the findings by the Institute of Medicine of the National Academy of Sciences which, in 1999, was commissioned through congressional legislation to study the safety of silicone breast implants. The Institute of Medicine's 400-page report by an independent committee of 13 scientists demonstrated no causal link between silicone implants and systemic diseases (11). Similarly, implants were not felt to be the cause of any connective tissue disorder or cancer. They did, however, conclude that breast implants were responsible for localised problems such as capsular contracture.

Numerous independent reviews of breast implant safety such as that by the Institute of Medicine have been conducted. These include the World Health Organization, Health Canada, and the European Committee on Quality Assurance and Medical Devices in Plastic Surgery. They have all reached similar conclusions regarding the safety and efficacy of silicone breast implants.

\section{CONCLUSION}

Breast augmentation remains an increasingly popular option today where the idealised female physique has morphed from the curvaceous Rubens type to one increasingly thin and androgynous, but with prominent breasts. From humble, and perhaps somewhat disorganised, beginnings the silicone gel prosthesis has now been accorded an, almost, clean bill of health. Whilst the dark years of the 1990s make for interesting reading, they at least catalysed a body of scientific evidence for surgeons and patients alike. It also demonstrates the requirement for science to be sufficiently robust to withstand highjack and subversion from a sensationalist, and not always patient-centred media, and for all parties to show patience with pioneers of novel techniques. The knee-jerk, anti-silicone foray into hydrogel and soya bean fillers was readily accepted due to the pervasive 'junk science' furore, but may now be regarded as ill-considered. Certain legal teams enriched themselves massively at the expense of ill-prepared organisations, such as Dow Corning, and one can only wonder at the outcome of a challenge against such a plaintiff counsel from a patient forced into accepting a Trilucent implant. Breast augmentation is a safe, well-accepted technique, which can be undertaken with ever-less frequent complications thanks to continued advances in both technique and implant design.

\section{REFERENCES}

1. Shipley RH, O’Donnell JM, Bader KF. Personality characteristics of women seeking breastaugmentation, comparison to small-busted and average-busted controls. Plast Reconstr Surg1997; 60(3): 369-76.

2. Baker JL Jr, Kolin IS, Bartlett ES. Psychosexual dynamics of patients undergoing mammaryaugmentation. Plast Reconstr Surg1974; 53(6): 652-9.

3. Cronin TO, Gerow FJ. Augmentation mammoplasty: a new natural feel prosthesis. Transactions of the Third International Congress of Plastic Surgery, October 13-18, 1963. Amsterdam: Excerpta Medica Foundation; 1963; 41-9.

4. Maxwell GP, Gabriel A. The evolution of breast implants. Clin Plast Surg 2009; 36(1): 1-13.

5. Terry MD, Skovron ML, Garbers S, et al. The estimated frequency of cosmetic breast augmentation among U.S. women 1963 through 1988. Am J Public Health 1995; 85(8 Pt 1): 1122-4.

6. Hetter GP. Satisfaction and dissatisfaction of patients with augmentation mammoplasty. Plast Reconstr Surg 1979; 64(2): 151-5.

7. Sarwer DB. The psychological aspects of cosmetic breast augmentation. Plast Reconstr Surg 2007; 120(7 Suppl 1): 110S-117S.

8. Czerny V. Plastic replacement of the breast with a lipoma [in German]. Chir Kong Verhandl 1895; 2: 216 .

9. Longacre JJ. Correction of the hypoplastic breast with special reference to reconstruction of the "nipple type breast" with local dermofat pedicle flaps. Plast Reconstr Surg 1954; 14(6): 431-41.

10. Picha GJ, Batra MK. Breast augmentation. In: Achauer BM, Eriksson E, Guyuron B, et al,eds. 
Plastic Surgery: Indications, Operations, and Outcomes. 1st ed. St. Louis, MO: Mosby; 2000: 2743-56.

11. Institute of Medicine. Safety of Silicone Breast Implants. Washington, DC: National AcademyPress; 1999.

12. Bondurant $S$, Ernster V, Herdman R, eds. Safety of silicone breast implants. Washington, DC: National Academy Press; 2000.

13. Uchida J. Clinical application of crosslinked dimethylpolysiloxane, restoration of the breast, cheeks, atrophy of infantile paralysis, funnelshaped chest, etc. Jpn J Plast Reconstr Surg 1961; 4: 303.

14. Boo-Chai K. The complications of augmentation mammaplasty by silicone injection. Br J Plast Surg 1969; 22(3): 281-5.

15. Ortiz-Monasterio F, Trigos I. Management of patients with complications from injections of foreign materials into the breasts. Plast Reconstr Surg1972; 50(1): 42-7.

16. Brown JB, Fryer MP, Randall P, et al. Silicones in plastic surgery: laboratory and clinical investigations, a preliminary report. Plast Reconstr Surg 1953; 12(5): 374-6.

17. Marzoni FA, Upchurch SE, Lambert CJ. An experimental study of silicone as a soft tissue substitute. Plast Reconstr Surg 1959; 24: 600-8.

18. Feng LJ, Amini SB. Analysis of risk factors associated with rupture of silicone gel breast implants. Plast Reconstr Surg. 1999; 104(4): 955-63.

19. Caffee HH. The influence of silicone bleed on capsule contracture. Ann Plast Surg 1986; 17(4): 284-7.

20. Berry MG, Davies DM. Breast augmentation: Part I- A review of the silicone prosthesis. J Plast Reconstr Aesthet Surg 2010; 63(11): 1761-8. doi: 10.1016/j.bjps.2009.07.047. Epub 2009 Aug 27.

21. Arion HG. Retromammary prosthesis. C R Soc Fr Gynecol 1965; 5.

22. Rees TD, Guy CL, Coburn RJ. The use of inflatable breast implants. Plast Reconstr Surg 1973; 52(6): 609-15.

23. Young VL, Watson ME. Breast implant research: where we have been, where we are, where we need to go. Clin Plast Surg 2001; 28(3): 451-83.

24. Lavine OM. Saline inflatable prostheses: 14 years' experience. Aesthetic Plast Surg 1993; 17(4): 325-30.
25. Al-Sabounchi S, De Mey AM, Eder H. Textured saline-filled breast implants for augmentation mammaplasty: does overfilling prevent deflation? A long-term follow-up. Plast Reconstr Surg 2006; 118(1): 215-22; discussion 223.

26. Hartley JH. Specific applications of the double lumen prosthesis. Clin Plast Surg 1976; 3(2): 247-63.

27. Colon GA. The reverse double-lumen prosthesisa preliminary report. Ann Plast Surg 1982; 9(4): 293-7.

28. Becker $\mathrm{H}$. The expandable mammary implant. Plast Reconstr Surg 1987; 79(4): 631-7.

29. Ashley FL. A new type of breast prosthesis. Preliminary report. Plast Reconstr Surg 1970; 45(5): 421-4.

30. Capozzi A, Pennisi VR. Clinical experience with polyurethane-covered gel-filled mammary prostheses. Plast Reconstr Surg 1981; 68(4): 512-20.

31. Melmed EP. Polyurethane implants: a 6-year review of 416 patients. Plast Reconstr Surg 1988; 82(2): 285-90.

32. Hester TR Jr, Nahai F, Bostwick J, et al. A 5-year experience with polyurethane-covered mammary prostheses for treatment of capsule contracture, primary augmentation mammoplasty, and breast reconstruction. Clin Plast Surg 1988; 15(4): 569-85.

33. Sinclair TM, Kerrigan CL, Buntic R. Biodegradation of the polyurethane foam covering of breast implants. Plast Reconstr Surg 1993; 92(6): 1003-13; discussion 1014.

34. Hester TR Jr, Tebbetts JB, Maxwell GP. The polyurethane-covered mammary prosthesis: facts and fiction. Clin Plast Surg 2001; 28(3): 579-86.

35. Maxwell GP, Hammond DC. Breast implants: smooth versus textured. Advances in Plastic and Reconstructive Surgery 1993; 9: 209.

36. Danino AM, Basmacioglu P, Saito $S$, et al. Comparison of the capsular response to the Biocell RTV and Mentor 1600 Siltex bre.ast implant surface texturing: a scanning electron microscopic study. Plast Reconstr Surg 2001; 108(7): 2047-52.

37. Hakelius L, Ohlsen L. Tendency to capsule contracture around smooth and textured gelfilled silicone mammary implants: a 5-year follow-up. Plast Reconstr Surg 1997; 100(6): 1566-9. 
38. Burkhardt B, Eades E. The effect of Biocell texturizing and povidone-iodine irrigation on capsule contracture around saline-inflatable breast implants. Plast Reconstr Surg 1995; 96(6): 1317-25.

39. Malata CM, Felderg L, Coleman DJ, et al. Textured or smooth implants for breast augmentation? Three year follow-up of a prospective randomized controlled trial. Br J Plast Surg 1997; 50(2): 99-105.

40. Burkhardt BR, Demas CP. The effect of Siltex texturing and povidone-iodine irrigation on capsule contracture around saline inflatable breast implants. Plast Reconstr Surg 1994; 93(1): 123-8; discussion 129-30.

41. Heden P, Jernbeck J, Hober M. Breast augmentation with anatomical cohesive-gel implants. Clin Plast Surg 2001; 28(3): 531-52.

42. Ersek RA, Salisbury AV. Textured surface, nonsilicone gel breast implants: four years' clinical outcome. Plast Reconstr Surg 1997; 100(7): 1729-39.

43. Spear SL, Mardini S. Alternative filler materials and new implant designs. Clin Plast Surg 2001; 28(3): 435-43.

44. Chaudhary S, Cadier MAM. Local tissue reactions to oil-based breast implant bleed. $\mathrm{Br}$ J Plast Surg 2000; 53(4): 317-8.

45. Papanastasiou S, Odili J, Newman P, et al. Are triglyceride breast implants really biocompatible? Ann Plast Surg 2000; 45(2): 172-3; discussion 174-6.

46. Ashley FL. Further studies on the natural-Y breast prosthesis. Plast Reconstr Surg 1972; 49(4): 414-9.

47. Bronz G. A comparison of naturally shaped and round implants. Aesthet Surg J 2002; 22(3): 23846. doi: 10.1067/maj.2002.124759

48. Baeke JL. Breast deformity caused by anatomical or teardrop implant rotation. Plast Reconstr Surg 2002; 109(7): 2555-64; discussion 2568-9.

49. Steinbrech DS, Lerman OZ. Breast implants: background, safety and general considerations. In: In: Aston SJ, Steinbrech DS and Walden JL, eds. Aesthetic Plastic Surgery. Sounders-Elsevier 2009; 645-60.

50. Kessler DA, Merkatz RB, Schapiro RA. A call for higher standards for breast implants. JAMA 1993; 270(21): 2607-8.

51. Kessler DA. The basis of the FDA's decision based on breast implants. N Engl J Med 1992; 326(25): 1713-5.
52. Hölmich LR, Lipworth L, McLaughlin JK, et al. Breast implant rupture and connective tissue disease: a review of the literature. Plast Reconstr Surg 2007; 120(7 Suppl 1): 62S-69S.

53. Deapen D. Breast implants and breast cancer: a review of incidence, detection, mortality, and survival. Plast Reconstr Surg 2007; 120 (7 Suppl 1): $70 \mathrm{~S}-80 \mathrm{~S}$.

54. Venkataraman S, Hines N, Slanetz PJ. Challenges in mammography: part2, multimodality review of breast augmentation- imaging findings and complications. AJR Am J Roentgenol 2011; 197(6): W1031-45. doi: 10.2214/AJR.11.7216. 